\title{
Analysis on General Characteristics and Differences of the Development of Public Goods Supply in Developed Countries
}

\author{
Meiying Yang \\ College of Economic and Management, Changchun University of Science and Technology \\ Changchun 130022, China \\ $\&$ \\ Business School, Jilin University, Changchun 130012, China \\ E-mail: yangmy996@139.com
}

Received: June 7, 2011

Accepted: July 28, 2011

doi:10.5539/jsd.v4n4p259

Fund Item: The article is phase achievements of Jilin social science fund project "Exploration and Analysis on the Path of Public Goods Supply under Overall Planning in Jilin Province” (item number: 2011B397).

\begin{abstract}
The development process and system mode of public goods supply in developed countries have directive significance. Starting from investigating the development process of public goods in developed countries, based on the analysis of general characteristics and differences of the development of public goods supply in developed countries the article explores the fundamental law of the development of public goods supply.
\end{abstract}

Keywords: Developed countries, Public goods supply, General characteristics, Differences

Public goods supply in developed countries has experienced long-term development and formed relative mature and steady supply system and mechanism. Doing research on general characteristics and differences of the development of public goods supply in developed countries in depth and seriously summing up the fundamental law of the development of public goods supply in developed countries have important practical significance.

\section{The development process of public goods supply in developed countries}

1) The development of public goods supply in period of traditional agriculture society

Public goods supply in developed countries existed in long period of traditional agriculture society. But because the development of commodity economy was very backward and the level of social public demand was very low, the development of public goods supply in developed countries was very slow during this period of time, whose scale was very limited, supply range was very small, contents were simple and structure was abnormal. Public goods supply was mainly limited to order maintenance such as national defense, guaranteeing military security and maintain national dominance as well as factors of production that adapts to the development of agricultural agriculture and husbandry, and urban handicraft industry. Such public goods supply in the aspect of social welfare as culture and education, sanitary and medical services, healthcare and social security was still vacant and blank. In the later period of agriculture society, with the further development of urban handicraft industry, factors of capitalism had begun to breed and grow, the situations of the development of commodity economy and urban handicraft industry, especially for the development of foreign trade, had changed, but on the whole, there was a kind of independent, imbalanced and unsustainable developmental tendency.

2) The development of public goods supply in period of capitalist industrialization

With the development of capitalist mode of production and rise of social productivity marked by large-scale industrial production machines, the features of public goods supply in developed countries made profound changes. The content of public goods supply became increasingly rich and various, their types became more complete, their system became perfect, and its supply range began to break through urban-rural chasm, expanding from cities to countries. In particular, the structure of public goods supply changed obviously. 1) in order to adapt to the need of industrialized development, such public goods as order maintenance increased a series of new contents in the aspect of policy and system which reflected the changes of times and aimed to 
guaranteeing the effective operation of market mechanism and the development of capitalism productivity and production relations, which made their composition further reasonable and perfect. 2) Such public goods supply as factors of production including social infrastructure related to social production and life obtained unprecedented rapid development, which became the important part in supply structure and had important position. 3) Such public goods supply as social people's livelihood including basic compulsory education, public health care, relief of poverty, social equity, social security and public welfare begun to develop to certain degree.

3) The development of public goods supply since the middle of $20^{\text {th }}$ century

After the Second World War, with the rise of the third scientific and technological revolution, public goods supply in developed countries had made unprecedented new changes. During this period, the scale of such public goods supply as order maintenance and factors of production in developed countries further expanded, their contents became richer and various, the system became more complete, the structure become more reasonable and their supply quality also made obvious changes. Meanwhile, public goods supply such as social people's livelihood in developed countries also obtained rapid and comprehensive development. Particularly, after the explosion of the world economic crisis, based on carefully reflecting and reviewing the position and role of government in social economic development, that developed countries increased public goods supply such as social people's livelihood became one important task and main content that the government made up market failure and intervened social economic development. And thus such public goods supply as social people's livelihood including basic compulsory education, public health care, relief of poverty, social equity, social security and public welfare obtained comprehensive and high-speed development. Favorable welfare policy, high-standard medical services, high-quality public education and so on became main patterns and contents in the structure of public goods supply.

\section{General characteristics of the development of public goods supply in developed countries}

Affected by the aspects including the phase of economic development, economic system, historical and cultural backgrounds as well as government intervention in the economy in developed countries, the development process of public goods supply has its own differences and characteristics, but generally, most of mature public goods supply has following common characteristics:

1) The tendency of the development of public goods supply in developed countries is same.

Public goods supply in developed countries not only experienced the development process comprised by different historical phases but also experienced one gradual and well-organized process from lower level to higher level, from simple to complex, from close to open, and from imperfect to perfect. Because of different national situations in different countries, the public goods supply in some countries developed quickly while the others developed slowly. Because of the influence, the track of the development of public goods supply was different. But from the perspective of final developmental tendency, different countries' public goods supply had unitary common characteristic along the same direction and the tendency was irreversible. Finally each country's public goods supply, even the universe public goods supply will go ahead along this kind of rising tendency. This is the general law of public goods supply, which do not repel different countries, nationalities and regions, and is shown and reflected by the rich and colorful diversity of public goods supply in specific developmental processes.

2) The changes of the contents, ranges and structure of public goods supply have internal homoplasy.

The contents of public goods supply in developed countries generally develop from simple, incomplete, not rich and systematic status to diverse, rich, complete and systematic. Its supply range basically develop from small range, limited coverage, rural and urban imbalance as well as unequal distribution in regions and districts in traditional society to continuously expand in the range, extensively cover rural and urban area and imbalance in the distribution in regions and districts. Its supply structure also has high consistency. Such public goods as social order maintenance experienced the changes from mainly meeting the needs related to agricultural production and development including national defense, administrative management in traditional society to attaching more importance to satisfy the needs of socialization, industrialization, marketization, urbanization and internalization. Such public goods as public factors of production experienced the changes from limitation to the infrastructure such as agriculture hydraulics and roads, to traffic transportation, electrical power, communication, infrastructure and basic sectors which were unnecessary for social economic takeoff and development in industrial society, then to such public goods supply as public factors of production needed by modern economic development. Such public goods as social people's livelihood also experienced the changes from basically blank to certain degree of development in industrial society, then to suddenly rises in modern society. 
3) The subjects and methods of public goods supply have homoplasy

From the perspective of the process of the development of public goods supply in developed countries, no matter in history or modern times, the government is the subject of public goods supply and has leading position in public goods supply. The difference is that the government was the sole subject of public goods supply in freely competitive capitalist period and they provided public goods through the way of unit exclusion. But since 1970s, in order to eliminate the drawbacks existing in unit exclusive supply, developed countries changed the pattern that only the government supplied public goods in succession. They relaxed the conditions of admittance to the field of public goods supply and made the market power with strength had access to the field of public goods. And thus the subjects of public goods supply realized the transformation from the government to multi-subjects including the government, private enterprises, communities, non-governmental organizations and international organizations, which formed tendency of the diversity of the subjects of public goods supply. In order to adapt to the process of the diversity of the subjects of supply, the methods of public goods supply in developed countries also showed the changes of increasingly diverse. Besides the governmental supply, various supply methods including blended supply, non-governmental organizational supply and individual supply also appeared and each method also had various forms.

4) The governmental functions and public goods supply mechanism transformation in developed countries has homoplasy.

Developed countries are market economy countries, and their public goods supply is realized by market mechanism, But market mechanism also has failure phenomenon in allocating resource, especially they cannot effectively provide the public goods such as infrastructure, social employment, social security, education, science and technology, culture, sanitation and sports, whose supply is necessary for social and economic stabilization and development. In order to overcome the drawbacks, developed countries intervened such public fields as compulsory education, medical health-care, social security, the redistribution of civil income and environmental protection in succession and continuously expanded the functions of public goods supply. When transforming governmental functions, developed countries paid more attention to how to use limited resources and cheap cost to create more high-quality and high-efficiency public goods and provide more comprehensive and high-efficiency public goods for the society. Since 1980s, there was a tendency of transforming public goods supply mechanism in succession and the mode of new public management mechanism formed. While realizing the competition between the public, the competition between the public and the private as well as the private and the private were encouraged, and thus the organic integration between public mechanism and market mechanism was realized, which better brought the functional advantages of the government and the market into play.

\section{The differences of the development of public goods supply in developed countries}

Although public goods supply in developed countries has some common characteristics in the subjects, contents, structure, mechanism, the role of the government and the developmental direction and tendency, affected by the differences of social economic developmental level, system, policy and historical and cultural backgrounds, developed countries have obvious differences in the aspects of the subjects of public goods supply, method, mechanism and the role of the government.

Firstly, developed countries have differences in the subjects and methods of public goods supply.

The market economy of developed countries is very mature and they allocated resources through market. But the differences of the modes of market economy mechanism in developed countries lead to the differences of the subjects and method of public goods supply in developed countries. Generally, in the countries that praise free market economy highly, market concentration is high, social middle organizations such as church, the chamber of commerce, union, club, folk charity, folk education organizations and other voluntary organizations are developed, which undertake various public affairs and prompt the diversity of the subjects and methods of public goods supply. For example, the USA is a country of free market economy and praises the freedom of individual economic activities. Giving priority to efficiency is the primary principle that the government provides public goods. Its diversity of the subjects and the methods of public goods supply comply with the aim of efficiency maximum and is the concentrated reflection that motivate social enthusiasm and creativity to the maximum to participate in public goods supply. On the contrary, some welfare-market-economy countries in northern Europe with the same developed economy take fairness as the primary concept of values, emphasize on the country as the subject, and practice general public goods supply and security for all the national people, whose tendency of the diversity of the subjects and methods of public goods supply are quite different from the USA.

Secondly, developed countries have differences in the aspect of the mechanisms of public goods supply. 
In the aspect of public goods supply mechanism, there are also differences between developed countries, which reflects mainly on how to coordinate and apply to public mechanism and market mechanism. More northern European countries adopt high-welfare public goods supply mechanism to provide basic security from cradle to grave for their residents and realize the supply of public goods through governmental financial expenditure. Although it better reflects fairness, it also creates pressure for the improvement of social and economic development, which limits the competition in high-welfare countries. On the contrary, the USA that has leading position in international competition introduces market mechanism into public goods supply, making governmental mechanism and market mechanism integrates organically and adopting to marketized method more. Only taking the example of providing the basic public goods such as education, besides free compulsory education, the USA attempted to coordinate governmental mechanism and market mechanism in higher education. Meanwhile, American government also provided financial support to community colleges and vocational schools and formed educational system with extensive teaching levels and high popularity rate of higher education. Under new international situations, such high-welfare countries such as Sweden, Denmark and UK also took all measures to improve the efficiency of welfare public goods supply and carried out reforms attempt which took the marketization of public goods supply as the main contents in succession, but generally, there are obvious differences in the marketized ranges, degrees and sustainability of public goods supply between welfare countries and countries free market mechanism.

Thirdly, the extent of the role of the government in developed countries' public goods supply has differences.

In public goods supply in developed countries, the extent of the role of the government has differences and shows its own characteristics, which generally are clarified to three situations: weak, strong and intermediate. In typical market economy countries, because their basic values appraises economic freedom highly and opposite to limit this kind of freedom, the role of the government is based on making up market failure, and the field that the government supplies public goods is limited to the one of market failure. Only when enterprises are unwilling or unable to invest and manage, or the efficiency that the corporate invest is lower, the government is needed to enter to make up. Therefore, in typical market economy countries, for example, American governmental public goods supply is to realize macro-control target to make up market failure, the country cannot guarantee everyone enjoy this basic social welfare such as medical insurance, which shows the extent of the role of the government is very weak in public goods supply. Different from typical market economy countries, for welfare-developed countries with similar economic and social development, because the government practice welfare capitalism policy and state monopoly capitalism, the government pays more attention to fairness when providing public goods firstly, and the field that supplies public goods is not limited to the field of market failure and take part of private products into the range of public goods supply and practice coverall social welfare system from cradle to grave. Obviously, the extent of the role of the government of welfare countries is very strong in public goods supply. In addition, the extent of the role of some countries is immediate in public goods supply. They think the government of free market economy countries pays more attention to efficiency and the fairness problems are obvious while the government of welfare countries pays more attention to fairness and the problems of efficiency are very serious. Considering that the role of both two kinds of government has their disadvantages in the development of public goods supply, the extent that emphasize on the role of government should be between them. The government does not exclude the capacity and activity that individual supplies public goods but should standardize their supply through policy in order to avoid supply obstacles.

\section{References}

Chen, Zhimei \& Liu, Lannan. (2008). Analysis on the imbalance of China's public goods supply. Journal of Beijing Technology and Business University. 2008, (2).

Chi, Fulin. (2008). speed up the equalization of basic public services. Review of Economic Research. 2008(3):19.

Song, Min. (2007). The effects and enlightenment of the market reform of public services in western countries. Economic Review. 2007(4): 63.

UNDP. (1993). UNDP and Organization of Civil Society. New York, 1993.1.

Yang, Meiying. (2008). Research on Overall Planning for Public Goods Supply in China. Changchun: Northeast Normal University.

Yu, Keping. (2006). China's civil society: concept, classification and system environment. Social Sciences in China Press. 2006, (1). 